\title{
PERANAN PASUKAN POLISI PELAJAR PERTEMPURAN DAN GEREJA PUGERAN DALAM REVOLUSI INDONESIA TAHUN 1948 - 1949 DI YOGYAKARTA
}

\begin{abstract}
Drs. Djumarwan
Danar Widiyanta, M.Hum*

Abstract

Yogyakarta is one city that witnesses the struggle of the people in defending the independence of Indonesia. In the Second War of Independence, all levels of society involved such as the Pasukan Polisi Pelajar Pertempuran (P3). This troop is a Mobile Briagade (Mobbrig) under the leadership of IP II Djohan Soeparno. The headquartered of this force was in SPN Ambarukmo Yogyakarta. P3 troops also played a role in Serangan Umum 1 March 1949. They were divided into several locations including the Benteng Wetan, Kotagede, Pleret and Karangsemut. The attacks of P3 was quite tiring for the Netherlands. War of Independence II also involves the whole society. One of them was the role of Gerja Pugeran located in Pugeran Bantul. At the time of the war this church serves as a refuge, hospitals, and public kitchen. In this church there are also many soldiers who asked for protection during the day. The Church also provides food for the refugees.
\end{abstract}

Key Words : Polisi Pelajar Pertempuran, Pugeran Church, Yoguakarta.

\begin{abstract}
Abstrak
Yogyakarta merupakan salah satu satu kota yang menjadi saksi perjuangan para rakyat dalam mempertahankan kemerdekaan Indonesia. Dalam Perang Kemerdekaan II, seluruh lapisan masyarakat terlibat tidak terkecuali Pasukan Polisi Pelajar Pertempuran (P3). Pasukan ini merupakan pasukan Mobile Briagade (Mobbrig) di bawah pimpinan IP II Djohan Soeparno. Pasukan ini bermarkas di SPN Ambarukmo Yogyakarta. Pasukan P3 juga berperan dalam Serangan Umum 1 Maret 1949. Mereka dibagi dalam beberapa lokasi diantaranya yaitu Pojok Benteng Wetan, Kotagede, Pleret, dan Karangsemut. Serangan yang dilakukan P3 cukup melelahkan bagi Belanda. Perang Kemerdekaan II juga melibatkan seluruh lapisan masyarakat. Salah satunya yaitu peran dari Gerja Pugeran yang terletak di Pugeran Bantul. Pada saat perang gereja ini berfungsi sebagai tempat pengungsian, rumah sakit, dan dapur umum. Di dalam gereja ini juga tinggal banyak tentara yang meminta perlindungan pada siang hari. Gereja juga menyediakan bahan makan untuk para pengungsi.
\end{abstract}

Kata Kunci : Polisi Pelajar Pertempuran, Gereja Pugeran, Yoguakarta.

\section{A. Pendahuluan}

Pada akhir Desember tahun 1948, Indonesia mendapat serangan secara tiba-tiba dari Pasukan Belanda melalui Lapangan Terbang Maguwo. Dalam serangan tersebut pasukan Tentara Nasional Indonesia (TNI) sedang ditugaskan di beberapa wilayah demarkasi. Pasukan yang masih berjaga di Yogyakarta di antaranya yaitu 3 Kompi Polisi Negara, dan CPM, 2 Seksi dari Brigade 10 Divisi III yang terdiri dari Seksi Brigade dan Seksi Batalion, 2 pleton Militer Akademi, Kesatuan Polisi Pelajar dari MBBDKN, Tentara Pelajar, dan beberapa kesatuan pejuang yang tidak mempunyai tugas khusus. ${ }^{1}$

Laju pasukan Belanda dihambat oleh pasukan yang berjaga di Yogyakarta. Seperti pasukan salah satu kesatuan dari MBBDKN yaitu Polisi Pelajar Pertempuran (P3) di bawah pimpinan Djohan Soeparno. Markas P3 pada awalnya di SPN Ambarukmo sebelum terdesak oleh Pasukan

\footnotetext{
${ }^{*}$ Staf Pengajar Prodi Ilmu Sejarah FIS UNY

${ }^{1}$ Atim Supomo, Djumarwan, dan Masqudori, Brimob Polri Jateng dan DIY dalam Lintasan Sejarah, (Yogyakarta: Pustaka Pelajar, 1996), hlm. 99.
} 
Belanda. Pasukan ini menghambat laju pasukan Belanda di daerah Janti sesuai dengan Perintah Kilat yang dikeluarkan oleh Panglima Besar Jendral Soedirman. Polisi Pelajar Pertempuran ini memiliki peran atau andil dalam Perang Kemerdekaan II.

Perang Kemerdekaan II ini merupakan Perang yang menggunakan strategi perang rakyat semesta. Strategi ini melibatkan seluruh lapisan masyarakat Indonesia. Salah satunya yaitu Gereja Hati Kudus Yesus Pugeran. Gereja Hati Kudus Yesus Pugeran terletak di Jalan Bantul Kota Yogyakarta memiliki peran penting dalam Perang Kemerdekaan. Gedung dari gereja dipakai untuk dapur umum, dan tempat pengungsian. Romo A. Sandiwan Brata Pr. terpanggil hatinya untuk melindungi dan mengayomi para pengungsi.

Rumusan masalah dalam penelitian ini adalah Bagaimana kondisi Yogyakarta pasca proklamasi? Bagaimana sejarah pembentukan kesatuan Polisi Pelajar Pertempuran dan peran dari Polisi Pelajar Pertempuran dalam Perang Kemerdekaan? Bagaimana peran dari Gereja Hati Kudus Yesus Pugeran dalam Perang Kemerdekaan?

\section{B. Kondisi Yogyakarta Pasca Proklamasi Kemerdekaan}

\section{Yogyakarta sebagai Ibu Kota Negara}

Propinsi Daerah Istimewa Yogyakarta secara resmi terbentuk sejak 4 Maret 1950, yaitu melalui UU No. 3 Tahun 1950. Akan tetapi kehadiran daerah ini sebagai daerah istimewa sedah ditetapkan dua hari setelah Presiden Soekarno memproklamirkan kemerdekaan Indonesia. Dengan suatu piagma yang ditandatangani oleh Presiden Soekarno, Sri Sultan Hamengku Buwono IX dan Paku Alam VIII dipercayakan untuk tetap pada kedudukanya masing-masing.

Setelah peristiwa proklamasi tanggal 17 Agustus 1945, para petugas kantor Domei pusat Jakarta berusaha agar berita proklamasi dapat disiarkan ke pelosok negeri. Berita proklamasi yang disiarkan pada siang hari sekitar pukul 12.00 berhasil diterima oleh kantor berita Domei cabang Yogyakarta yang saat itu bertempat di Gedung Perpustakaan Negara bagian atas di Jalan Malioboro. ${ }^{2}$ Berita tersebut kemudiai secara diam-diam disebarkan melalui mulut ke mulut. Dengan demikian berita proklamasi tersebut cepat tersebar secara luas di kalangan masyarakat, sampai desa-desa dan dusun.

Sri Sultan Hamengku Buwono dan Sri Paduka Paku Alam VIII merasa bahagia mendengar berita proklamasi tersebut. Pada tanggal 19 Agustus 1945, Sri Sultan Hamengku Buwono IX dan Sri Paduka Paku Alam VIII mengucapkan selamat atas berdirinya Negara Republik Indonesia dan selamat atas terpilihnya Soekarno sebagai presiden dan Moh. Hatta sebagai wakil presiden. Selain, itu dalam surat kabar Sinar Matahari yang terbit anggal 20 Agustus 1945, memuat sambutan pidato Sri Sultan Hamengku Buwono IX tentang proklamasi

\footnotetext{
2 Tashadi H, dkk, Buku Kenangan 50 Tahun Republik Indonesia di Yoyakarta sebuah Lintasan Sejarah, (Yogyakarta: Panitia Gabungan Peringatan HUT ke-50 Kemerdekaan RI Bhakti Pertiwi Propinsi Daerah Istimewa Yogyakarta, 1995), hlm. 50,
} 
kemerdekaan yang intinya mengimbau kepada seluruh Bangsa Indonesia untuk berkorban demi kepentingan bersama yaitu menjaga, memelihara, membela kemerdekaan nusa dan bangsa. ${ }^{3}$

Keamanan di ibu kota Jakarta menjadi tidak aman Pada saat itu pihak Belanda di Jakarta melakukan tindakan teror terhadap diri pemimpin Republik Indonesa, antara lain terhadap Sutan Sjahrir. Situasi dan kondisi di Jakarta tidak memungkinkan untuk digunakan sebagai ibu kota negara atau pusat pemerintahan Republik Indonesia. Untuk itu, pada tanggal 4 Januari 1946 ibu kota RI dipindahkan dari Jakarta ke Yogyakarta. Kepindahan ibu kota ke Yogyakarta diawali dengan berpindahnya Presiden Soekarno dan wakil Presiden Moh. Hatta yang kemudian diikuti oleh berpindahnya kementrian-kementrian dan secara berangsur wilayah Yogyakarta menjadi pusat pemerintahan Republik Indonesia.

Perpindahan ibu kota ke Yogyakarta mendorong pula berpindahnya rakyat-rakyat pribumi ke Yogyakarta untuk melanjutkan perlawanan kepada Belanda. Perpindahan penduduk tersebut menyebabkan bertambahnya penduduk kota Yogyakarta dari 170.000 jiwa menjadi 600.000 jiwa. Bertambahnya penduduk yang terjadi di Yogyakarta mengakibatkan semakin banyaknya pengangguran. Ekonomi pada saat itu sangat sulit dikarenakan Belanda memblokade perdagangan di wilayah Indonesia. Berpindahnya pusat pemerintahan disertai dengan berpindahnya instansi-instansi dan jawatan-jawatan pemerintahan ke Yogyakarta. Pada awalnya, organisasi pemerintahan belum sepenuhnya berjalan dengan sempurna seperti yang dikehendaki.

\section{Yogyakarta dalam Perang Kemerdekaan}

Belanda semakin gencar melakukan penekanan-penekanan untuk menduduki Indonesia kembali. Ambisi Belanda semakin terlihat pada saat Belanda mengadakan serangan militer yang dikenal dengan Agresi Militer Belanda I pada tanggal 21 Juli 1947. Agresi militer Belanda I disebut juga Perang Kemerdekaan pertama di Indonesia. Serangan besar-besaran tersebut dilancarkan pada tanggal 21 Juli 1947. Serangan tersebutn dipimpin oleh Gubernur Jenderal Van Mook. Alasan Belanda melakukan agresi militer Belanda yakni, yang pertama sudah berkali-kali diadakan pertemuan yang berlangsung lama dengan pihak Republik Indonesia namun tidak ada hasilnya. Kedua, pihak Republik Indonesia bersikeras memegang teguh pengertianya sendiri yang bertentangan dengan persetujuan Linggarjati. Ketiga pihak Republik menolak kedaulatan Belanda dan memperkosa milik Belanda. Keempat pemerintah Republik tidak kuasa lagi menjamin keamanan dan keadilan. Kelima sampai tanggal 15 Juli 1947 pemerintah Belanda sudah berusaha mencapai persetujuan dengan Menteri Amir tetapi ditolak oleh pihak Yogyakarta. $^{4}$

Dalam hal ini, PBB mengadakan komisi yang terdiri dari tiga negara yang dikenal dengan Komisi Tiga Negara. Komisi Tiga Negara tersebut beranggotakan dari Amerika Serikat, Belgia dan Australia. Pertemuan Komisi Tiga Negara ini dilakukan di Kaliurang, Yogyakarta.

\footnotetext{
${ }^{3}$ Ibid,. hlm. 51.

4 Tashadi dkk, Sejarah Revolusi Kemerdekaan (1945-1949) di DIY, (Yogyakarta, Departeman Pendidikan dan Kebudayaan, 1986), hlm. 111.
} 
Kemudian, Agresi Militer Belanda I ini, diakhiri dengan diadakannya Perjanjian Renville pada 14 Januari 1948.

Sebagai hasil Persetujuan Renville, pihak Republik harus mengosongkan wilayahwilayah yang dikuasai TNI, dan pada bulan Februari 1948, Divisi Siliwangi hijrah ke Jawa Tengah dan Yogyakarta. Di Yogyakarta, Divisi Siliwangi dapat diterima dengan baik oleh rakyat Yogyakarta. Akan tetapi, di Jawa Tengah tepatnya di Surakarta terdapat konflik antara Divisi Siliwangi dan Divisi Panembahan Senopati. Kondisi internal Republik Indonesia yang sedang kacau dimanfaatkan oleh Belanda untuk melakukan serangan atau Agresi Militer Belanda ke II.

Serangan atau Agresi Militer Belanda ke II dilakukan pada 19 Desember 1948. Serangan tersebut dimulai dengan penerjunan pasukan Baret Merah di Lapangan Terbang Maguwo (timur Kota Yogyakarta). Selain itu, pesawat-pesawat Belanda menyerang Maguwo dan dalam waktu singkat berhasil menduduki Maguwo dengan pasukan payungnya. ${ }^{5}$ Pada waktu itu Tentara Nasional Indonesia sedang tidak berada di dalam Yogyakarta, karena pasukan TNI sedang dikirim ke front barat (Gombong-Purworejo) untuk menghadapi serangan Belanda. Untuk itu di kota Yogyakarta hanya terdapat beberapa pasukan sisa diantaranya yaitu 3 kompi Polisi Negara dan CPM, 2 Seksi Kesatuan Brigade 10 Divisi III yang terdiri dari satu seksi Dekking-Staf Brigade dan satu Dekking Staf Batalyon dan 2 peleton Militer Akademi. ${ }^{6}$ Di samping itu juga terdapat beberapa kesatuan yang tidak mempunyai tugas-tugas khusus yaitu, Tentara Pelajar dan Polisi Pelajar dari Mobile Brigade Besar Djawatan Kepolisian Negara (MBBDKN).

Untuk mengatasi situasi Yogyakarta yang tidak menentu juga dibentuk Pemerintahan Militer di Yogyakarta. Tujuan dari pembentukan Pemerintahan Militer yaitu untuk mengusahakan agar ada suatu pemerintahan yang tegas dan dapat membantu militer dalam menhadapi Belanda. ${ }^{7}$ Pembentukan tersebut berdasarkan pengumuman dari Panglima Tentara dan Teritorium Jawa tertanggal 22 Desember 1948. Sejak diumumkanya instruksi tersebut maka secara taktis pemeritahan di JAwa berlaku Pemerintahan Militer Totaliter yang membawahi secara taktis pemerintahan sipil dengan basis kekuatan di desa-desa.

\section{Pembentukan dan Peranan Polisi Pelajar Pertempuran (P3) dalam Perang Kemerdekaan II}

\section{Pembentukan Brigadir Mobile (Brimob)}

Beberapa saat setelah proklamasi kemerdekaan Kepolisian Indonesia menyadari perlunya kesatuan pemukul dari kepolisian yang dapat diandalkan. Untuk tujuan tersebut, kepolisian Indonesia menyatukan kembali sebuah kompi Polisi Istimewa yang anggotanya terdiri dari polisi istimewa yang masih bujangan dan memiliki seishin (semangat juang) dan bersifat sukarela. Sejalan dengan semangat rakyat Indonesia untuk mempertahankan kemerdekaan Indonesia dan menjunjung tinggi kedaulatan negara Republik Indonesia, maka Komandan Tokubetsu Keitsatsu Tai Inspektur Polisi Tingkat I Moehammad Jasin bersama bersama dengan anggota polisi lainya

\footnotetext{
${ }^{5}$ Dharmono Hardjowidjono (ed), Replika Sejarah Perjuangan Rakyat Yogyakarta (Buku Ke-Satu), (Yogyakarta: Dinas Sosial Propinsi Daerah Istimewa Yogyakarta 1983), hlm. 230.

${ }^{6}$ Gerilya Wehkreise III, (Yogyakarta: Percetakan Keluarga,tt.), hlm 10.

${ }^{7}$ Ibid., hlm 13.
} 
menyatakan kebulatan tekad yang dituangkan dalam teks proklamsi dari pasukan polisi pada tanggal 21 Agustus 1945.

Tugas dari Polisi Istimewa adalah mempertahankan keamanandan ketertiban baik secara preventif dengan bertindak secara aktif dengan menggunakan senjata. Kesatuan-kesatuan Polisi Istimewa ini memiliki nama bermacam-amcam berdasarkan kebanggan masing-masing, misalnya Pasukan Gerak cepat, Pasukan Polisi perjuangan, Polisi Macan, dan ada pasukan yang tetap menamakan dirinya sebagai Pasukan Polisi Istimewa. Oleh karena dimaksudkan sebagai tulang punggung, maka Polsisi Istimewa memiliki pasukan penggempur yang mempunyai anggota-anggota yang terpilih. Polisi Istimewa digaji lebih tinggi dibanding polisi biasa. ${ }^{8}$

Di dalam usaha penyempurnaan Pasukan Polisi Istimewa Komisaris Polisi TK. I Soemarto yang ketika itu menjabat Wakil kepolisian Negara mempunyai inisiatif agar Pasukan Polisi Istimewa diubah namanya menjadi Mobile Brigade. Hal ini dilakukan denan pertimbangan agar menjadi kesatuan pasukan yang berdisiplin tinggi, kompak, loyal, dan penuh dedikasi, dan mampu bergerak secara cepat dan dinamis. ${ }^{9}$ Pada tanggal 17 September 1946, Kepala kepolisian RS. Soekanto Tjokrodiatmodjo, member kuasa kepada Komisaris Polisi M. Yasin untuk melakukan bebagai usaha persiapan pembentukan Mobile Brigade. Berdasarkan Surat perintah Muda Kepolisian No.Pol : 12/78/91 sejak tanggal 14 November 1946 secara resmi Mobile Brigade lahir.

Di setiap Karesidenan dibentuk Mobile Brigade Besar Karesidenan disingkat menjadi MBK. MBK berkekuatan 1 kompi yang anggotanya kurang lebih 100 orang dan dipimpin oleh seorang Inspektur Polisi (IP 1) dan Inspektur Polisi Kelas II (IP II). Administrasi dari MBK di bawah naungan Kepala Kepolisian Karesidenan. Pada intinya Mobile Brigade Karesidenan harus mengikut di tempat kedudukan Kepala Karesidenan. Di atas MBK dibentuk Mobile Brigade Besar Provinsi. Sedangkan di tingkat pusat dibentuk Mobile Brigade Besar Djawatan Kepolisian Negara (MBB-DKN). Pasukan Mobile Brigade terdiri atas tiga bagian yaitu, Mobile Brigade Besar Djawatan Kepala Pusat yang berada di Yogyakata, Mobile Brigade Besar Jawa Tengah, dan Mobile Brigade Jawa Timur yang dipimpin oleh Moehammad Jasin. MBB-DKN di bawah pimpinan Komisaris Polisi II RM. Broto Mardoekoesomo membawahi empat kompi sebagai berikut.

- Kompi I di bawah pimpinan IP II Rachmat Setiadiwirja berkedudukan di Ganjuran Bantul dan sebagian di Pura Pakualaman.

- Kompi II di bawah pimpinan IP RM. Bambang Soeprapto Dipoekoesoeko berada di Banyumas.

- Kompi III yang dipimpin IP I RM Djono Pitojo berada di Soli

- Kompi IV yang dipimpin IP II Djohan Soeparno berada di SPN Ambarukmo yang sekaligus dijadikan Markas Batalyon MBB-DKN.

\footnotetext{
${ }^{8}$ Atim Supomo, Djumarwan, dan Masqudori, op.cit., hlm. 16-17.

${ }^{9}$ Ibid., hlm. 27
} 
Senjata Mobile Brigade diperoleh dari pembelian dari rakyat atau bekas anggota-anggota tentara. Senjata tersebut terdiri dari karabin, mitraliur, owen gun, mouser pestool, dan stengun. Senjata-senjata api didapat oleh kenpetai di Kota Baru Yogyakarta. Selain itu para Penilik diperintahkan supaya Karesidenan lain dengan cara pengoperan senjata. Dalam pengoperan senjata tersebut harus dilaporkan kepada Jawatan Kepolisian negara bagian Perlengkapan dan bagian Organisasi (Tuan Siddik dan Tuan Ummarsaid). ${ }^{10}$

Perlengkapan yang lain setiap seksi dilengkapi dengan sebuah truk untuk memudahkan mobilisasi pasukan Mobbrig. Seluruh pasukan juga dihimbau untuk membawa perlengkapan untuk kebutuhan mereka seperti ransel, suling dari kuningan, tambang, pisau kecil, dan feldflesch dari alumunium. Seragam yang dipakai oleh pasukan Mobile Brigade adalah dua steel uniforms yang terdiri dari 1 bivakmust, 1 helmhuld dari bamboo (dengan emblemnya), 2 kemeja, 2 celana panjang, 1 pasang beenkap pendek dan 1 pasang sepatu. ${ }^{11}$ Pada awalnya para anggota Mobbrig menggunakan pakaian seadanya akan tetapi teratur.

\section{Pembentukan Pasukan Polisi Pelajar Pertempuran (P3)}

Di Sekolah Polisi Negara (SPN) Ambarukmo terdapat satu pasukan yang bermarkas yaitu Pasukan Polisi Pelajar Pertempuran (P3). Kompi ini merupakan kompi bentukan dari MBBDKN. Pemimpin dari pasukan Polisi Pelajar Pertempuran adalah Inspektur Polisi (IP) II Djohan Soeparno. Anggota dari pasukan P3 mayoritas merupakan para siswa Mobbrig yang sedang melakukan penataran dan bermarkas di SPN Ambarukmo.

Situasi yang genting akibat dari serangan Belanda pasukan P3 pindah markas ke Gunung Indrokilo dan setelah itu karena terdesak oleh pasukan Belanda pindah ke Desa Banjakan. Pada saat perang kemerdekaan, secara operasional P3 masuk di bawah komando Sub Wehkreise (SWK) 102 karena letaknya markasnya berada di Bantul. SWK 102 dipimpin oleh Mayor Sardjono. Selain Pasukan P3 di dalam SWK 102 terdapat pasukan Mobbrig yang dipimpin oleh PIP I. Musiman yang menggantikan IP.II Rachmat Setiadiwirja karena ditangkap Belanda. Selain iitu juga ada pasukan Kompi Soedarsono dari Battaliyon Sroehardjo, PAsukan Polisi Tohari, Tentaara Pelajar yang dipimpin oleh Rahardjo, pasukan Angkatan Udara Republik Indonesia (AURI) yang dipimpin oleh Basoeki dan Wirjo.

Pasukan P3 merupakan salah satu korps dari Mobbile Brigade yang masih menempuh pendidikan. Mereka diasramakan agar tidak mudah terpengaruh dari dunia luar, terjaga kesehatanya. kedisplinanya, terjaga moralnya dan agar mudah digerakkan secara cepat. Tugas pasukan P3 pada masa revolusi fisk selain mempertahankan kemerdekaan yaitu bertugas menangkap dan membunuh perampok dalam kota. Senjata yang dipergunakan oleh Pasukan P3 yaitu karabin, mitraliur, pistol, dan lain sebagainya.

\footnotetext{
${ }^{10}$ Hadiman, Lintasan Perjalanan Kepolisian RI Sejak Proklamasi hingga 1950, (Jakarta: PT. GPM, 1985), hlm. 250.

${ }^{11}$ Ibid., hlm. 251.
} 
Pasukan P3 dibagi menjadi beberapa regu, yaitu Regu Kairun menempati rumah Mbok Harjoutomo di Kloron Segoroyoso. Regu Sugiman, Regu Supardal, Regu Bagong, Regu Sukijo, Regu Mujo, Regu Sumarto, Regu Suharto, Regu Pengawal, dan Regu Hantu Maut. Sebagian pasukan bermarkas di Banyakan, akan tetapi Pasukan P3 juga tersebar di beberapa wilayah seperti, Gunung Indrokilo, Jambidan, Ngabalak Sitimulyo, Pamotan-Jlamprang, dan Watugender. Kantor staf dari pasukan P3 berada di Gunung Sanggrahan Kelurahan Sitimulyo. ${ }^{12}$ Anggota dari pasukan P3 tidak hanya terdiri dari pasukan polisi karena pada saat itu rakyat yang bertempat tinggal di sekitar markas P3 ikut gabung untuk mempertahankan kemerdekaan Indonesia.

\section{Peranan Polisi Pelajar Pertempuran (P3) dalam Perang Kemerdekaan II}

Indonesia kembali mendapat serangan besar dari Belanda pada pagi hari tanggal 19 Desember 1948. Serangan tersebut berhasil melumpuhkan Lapangan Terbang Maguwo Yogyakarta. Pada saat terjadi Agresi Militer ke-II pasukan tentara Indonesia sedang ditugaskan di beberapa daerah perbatasan sehingga terjadi kekosongan dan hanya tersisa pasukan Tentara Pelajar, tiga Kompi Pasukan Polisi negara , CPM, dua seksi kesatuan Brigade 10 Divisi III, dan Pasukan P3 dari Mobile Brigade Besar Djawatan Kepolisian Negara. ${ }^{13}$

Pasukan Polisi Pelajar Pertempuran yang sedang menuntut ilmu tersebut langsung menyebar ke daerah Janti hingga Timoho untuk melakukan penghambatan. belanda cukup direpotkan dengan penghambatan yang dilakukan oleh Pasukan P3. mestinya jarak MaguwoYogya bisa ditempuh hanya dalam waktu setengah ja, saja, tapi pada saat itu Belanda berhasil menduduki kota pada pukul 16.00 WIB. ${ }^{14}$ Penghambatan pasukan Belanda oleh Pasukan P3 bermanfaat bagi para petinggi yang melakukan sidang.

Perlawanan yang dilakukan oleh pasukan P3 tidak membuahkan hasil karena tidak seimbangnya pasukan Belanda dan P3 serta persenjataan yang dimiliki oleh P3 tidak mampu menandingi pasukan Belanda. Oleh karena itu, pasukan P3 ditarik mundur oleh IP II Djohan Soeparno. Sebagian pasukan P3 mundur menuju Godean melalui Kaliurang melewati Turi kemudian melewatu Jalan Magelang dan berakhir di Gamping dan Demakijo Sleman. Setelah mundur dari Ambarumo menuju Godean, pasukan P3 kembali bergabung dengan pasukan P3 lainya yang berada di Bantul. Mereka bergerak dari Godean ke selatan menuju BAntul kemudian melewati Ganjuran menuju Imogiri dan berakhir di Karangsemut. ${ }^{15}$

Sedangkan sebagian lagi mundur ke arah markas yang telah dipilih melalui Ambarukmo menuju Sapen kemudian mundur ke Lempuyangan, setelah itu menuju Gondomanan kemudian Imogiri ke Karangsemut dan kemudian bergeser ke timur menuju Desa Banyakan. ${ }^{16}$ Pasukan P3 bermarkas di rumah Hadirowi seorang pamong di Desa Banyakan. Walaupn berada di Banyakan,

\footnotetext{
12 Dharmono Hardjowidjono (ed), op.cit., hlm. 235.

${ }^{13}$ Ibid., hlm. 231.

${ }^{14}$ Polda Jawa Tengah, Sejarah Kepolisian Daerah Jawa Tengah Tahun 1945-1990, (Semarang: t.p. 1991 ), hlm 45.

${ }_{15}$ Abdul Haris Nasution, Sekitar Perang Kemerdekaan Indonesia Jilid 9, (Bandung: Angkasa, 1974), hlm. 227.

${ }^{16}$ Dharmono Hadiwijaya (ed), op.cit., hlm 235
} 
komunikasi antara pemimpin P3 dengan pemimpin SWK 102 dan Let Kol Soeharto yang bermarkas di Segoroyoso tidak pernah putus.

Setelah dilakukan koordinasi antar kesatuan di pusat gerilya masing-masing, maka segera dilakukan serangan balasan terhadap pos-pos militer Belanda baik di kota maupun di pinggiran kota. Sejak tanggal 29 Desember 1948 pasukan Belanda tidak berani keluar markas. ${ }^{17}$ Kalau siang hari kota Yogyakarta milik pasukan Belanda, tetapi setelah matahari terbenam maka seluruh kota menjadi milik pasukan gerilya, begitupun juga pasukan P3 yang mempunyai pasukan Hantu Maut yang beroperasi di sekitar Banyakan, Pleret dan Kotagede.

Sejak Letnan Kolonel Soeharto memindahkan Posko Wehkreise III dari Segoroyoso Pleret ke Bibis Bangunjiwo Bantul dalam rangka memudahkan koordinasi dengan pasukan lain menjelang Serangan Umum 1 Maret 1949. PAsukan P3 pada saat itu mempunyai wilayah yang digunakan untuk melakukan serangan yaitu di sekitar jalan Pleret-Kotagede. Pasukan P3 melakukan serangan terhadap patrol-patroli Belanda pada tanggal 23 hingga 25 Desember 1948. ${ }^{18}$

Untuk membalas dan menunjukkan kepada dunia bahwa Indonesia masih ada Sri Sultan Hamengku Buwono IX berinisiatif untuk melakukan Serangan Umum 1 Maret 1949 . Sri Sultan memerintahkan Let Kol Soeharto untuk mengkoordinasi semua pasukan yang ada di Yogyakarta. Semua pucuk pimpinan SWK diperintahkan untuk memberikan komando ke anak buah untuk mempersiapkan segala sesuatu untuk melakukan serangn umum. Di sektor selatan atau SWK 102 tempat kesatuan P3 di bawah mayor Sardjono melaksnakan perintah. IP II Djohan Soeparno pun mendapat perintah dari Mayor Sardjono untuk memperkuat serangan ke Yogyakarta pada tanggal 1 Maret 1949.

Sasaran dari P3 yaitu pos Belanda yang berada di Kotagede, Pleret, Pojok Benteng Wetan. Untuk membedakan antara musuh dan kawan setiap pasukan diberi tanda janur kuning yang dikenakan di setiap badan anggota. Untuk keperluan serangan umum tersebut, IP II Djohan Soeparno mempersiapkan sgala sesuatunya. Djohan Soeparno membagi pasukan P3 menjadi 3 seksi, diantaranya:

a. Seksi AP. Kairun yang dipimpin langsung oleh Wakil Komando Kompi yaitu M.A Tari. Seksi ini bertugas menyerang Pos Belanda yang berada di sebelah timur yaitu Pojok Benteng Wetan.

b. Seksi Supardal mendapat tugas ke Karangkajen dan sebagian memperkuat pasukan yang ada di Pojok Benteng Wetan.

c. Seksi AP. Sukidjo mendapat tigas ke Pleret. Seksi ini dibagi menjadi dua yaitu :

- Brigade AP. SUgiman mendapat tugas menyerang pos Belanda di Kotagede

\footnotetext{
${ }^{17}$ Atim Supomo, Djumarwan, Masqudori, op. cit., hlm. 98.

18 Seskoad, Serangan Umum 1 Maret Latar Belakang dan Pengaruhnya, (Bandung: Citra Lantoro Gung Persada, 1989), hlm. 136
} 
- Brigade AP. Suradi mendapat tugas menyerang pos Belanda di Karangsemut. ${ }^{19}$

Sesuai dengan instruksi dari Mayor Sardjono, IP II Djohan Soeparno pada tanggal 28 Februari 1949 mengadakan briefing atau pengarahan kepada semua pasukanya. Briefing dilaksanakan pada pukul 16.00 di Markas Besar P3 Banyakan. Pada pukul 22.00 tanggal 28 Februari 1949 pasukan AP Sukidjo mulai mendekati Daerah Pleret untuk melakukan serangan. Pasukan P3 juga berhasil merebut pos Belanda yang berada di daerah Barongan, Untuk mengamankan pasukanya, pasukan Belanda menarik diri dan mundur ke arah Kotagede.

Pada dini hari pasukan P3 tersebar di beberapa titik sesuai sasaranya. Begitu juga IP. II Djohan Soeparno bersiap-siap menyerang Pos Belanda di Kotagede menunggu fajar tiba. Pasukan P3 yang dipimpin oleh IP II M.A Tari telah bersiap-siap menyerang pojok Benteng Wetan bersama dengan pasukan 102 lainya, Pasukan P3 yang bertugas di pojok Benteng wetan berkekuatan sekitar 1 seksi/pleton. ${ }^{20}$ Setelah terdengar sirine seluruh pasukan yang sudah lama stelling langsung bergerak dan menuju sasaran masing-masing. Begitupun pasukan M.A Tari mulai melakukan serangan terhadap tangsi-tangsi. Dikarenakan kekuatan antara Belanda dan Pasukan P3 tidak seimbang semua pasukan ditarik mundur dan diarahkan menuju markas P3 di Banyakan. Seksi Kairun dan Supardal di bawah pimpinan M.A. Tari mengundurkan diri dari daerah Pojok benteng wetan setelah pukul 09.00 menuju ke tempat konsolidasi di Banyakan.

\section{Peranan Gereja Hati Kudus Yesus Pugeran pada Masa Perang Kemerdekaan II \\ 1. Berdirinya Gereja Hati Kudus Yesus Pugeran Yogyakarta}

Gereja Santo Fransiscus Xaverius yang dibangun oleh orang-orang Belanda tersebut terletak di sebelah selatan rumah orang-orang Belanda serta Kampemen Straat, sehingga gereja tersebut dikenal dengan gereja Kidul Ngloji. Gereja Santo Fransiscus Xaverius hanya diperuntukkan bagi orang-orang Belanda yang beragama katolik. Orang-orang Jawa yang beragama katolik dilarang masuk ke Gereja Santo Fransiscus Xaverius kecuali misdinar ${ }^{21}$ yang sedang bertugas. Untuk menampun jumlah umat uang semakin banyak dan untuk memnuhi kebutuhan tempat ibadat bagu umat katolik Jawa, maka di seblah timur gereja Santo Fransiscus Xaverius disirikan sebuah gerja yaitu gereja Santo Yusup. ${ }^{22}$ Untuk menampung banyaknya umat dan dalam rangka memperluas wilayah gereja ke berbagai daerah, maka didirikanlah secara berturut-turut gereja Santo Antonius di Kotabaru tahun 1926, gereja Santo Yusup di Bintaran tahun 1934 dan Gereja Hati Kudus di Pugeran tahun 1934.

Gereja Hati Kudus yang terletak di Pugeran merupakan gereja yang didirikan atas hasil pembelian tanah oleh Yayasan Papa Miskin Yogyakarta. Pembelian tanah kemudian

\footnotetext{
${ }^{19}$ Atim Supomo, Djumarwan, Masqudor, op.cit., hlm 102.

${ }^{20}$ Seskoad, op.cit., hlm 234.

${ }^{21}$ Misdinar merupakan pemuda atau pemudi yang melayani pastor dalam upacara gereja katolik atau pelayan misa.

${ }^{22}$ Gereja Santo Yusup merupakan gereja yang terletak di timur gereja Santo Fransiscus Xaverius. Gereja khusus untuk ibadah umat katolik yang berbahasa Jawa. Mulai pada saat itu gereja Santo Yusup dipakai untuk ibadah umat katolik pribumi (Jawa) dengan pengantar Bahasa Jawa.
} 
diatasnamakan kepada Romo. A. Djajasepoetra, SJ. ${ }^{23}$ Tanah yang dibeli tersebut terletak di seblah timur jalan Suryaden yaitu jalan antara Pojok Benteng sebelah barat dan BAntul, dan dikenal dengan nama Pugeran. Kampung Pugeran dipilh sebgai tempat untuk mendirikan gereja karena pada saat itu wilayah Yogyakarta selatan hanya terdapat satu gereja katolik yaitu Gereja Ganjuran yang terletak di Ganjuran Bantul. Gereja ini tidak bisa menampung jumlah umat katolik di wilayah Bantul.

Pada tanggal 5 November 1933, diadakan upacara peletakan batu pertama untuk membangun sebuah gereja dan pastoran di Pugeran. Pembangunan gereja selesai pada tanggal 16 April 1934, romo van Kalken menugaskan Romo Djajasepoetra dan Romo de Kuper sebagai pastor di gereja Pugeran. Dalam melaksanakan tugas kedua pastor tersebut bergiliran di gereja Santo Yusup Bintaran dan gereja Hati Kudus Pugeran. Masyarakat di sekitar gereja Pugeran kebanyakan terdiri dari orang-orang Jawa, maka untuk memenuhi kebutuhan agar dapat dapat menyesuaikan diri dengan masyarakat di sekiatrnya, Romo Djajasepoetra ditetapkan sebagai pastor gereja Hati Kudus Tuhan Yesus Pugeran. Pada hari Minggu tanggal 8 Juni 1934 gereja Hati Kudus Yesus Pugeran diresmikan.

\section{Peranan Gereja Hati Kudus Yesus Pugeran}

Pada masa Perang Kemerdekaan Gereja Pugeran digunakan sebagai tempat pengungsian atau penampungan sementara pengungsi dan sebagai tempat persembunyian para Tentara Republik Indonesia dari serangan tentara Belanda. Menurut para pengunsi dan tentara gereja Pugeran merupakan satu-satunya tempat yang dirasa aman untuk dijadikan sebagai tempat sementara pada masa Perang Kemerdekaan. Rumah-rumah di sebelah selatan Pojok Benteng oleh Belanda dibakar sehingga halaman gereja dan Pastoran Pugeran penuh dengan orang-orang mengungsi.

Sekitar pukul 00.30 Romo sandiwan bekeliling halaman gereja yang dipenuhi oleh para pengungsi. Pintu gerbang gereja penuh dengan orang-orang, termasuk juga Tentara Republik Indonesia. Pasukan Belanda memberlakukan jam malam dari pukul 18.00 dengan aturan rakyat pribumi yidak diperbolehkan melewati jalan raya depan gereja. Apabila ada yang berani melewati jalan raya tersebut maka akan ditembak mati oleh Belanda. Pada awalnya hanya terdapat sekitar 30an pengungsi tanpa persediaan makanan. Dengan surat keterangan dari Mayor Sypkens, Romo Sandiwan dan beserta salah seorang pengungsi menuju kota Yogyakarta untuk mencari bantuan makanan di pastoran Secodoningratan dan di sana mereka memperoleh bantuan lima kilogram beras. Selain meminta bantuan ke pastoran Secodoningratan, Romo sandiwan meminta bantuan kepada Mgr. Albertus Soegijapranata, SJ di pastoran Bintaran.

Pada tanggal 23 Desember 1948, terjadi pertempuran antara Republik Indonesia dan tentara Belanda. Medan pertempuran adalah jalan depan gereja Hati Kudus Pugeran, sehingga jalan tersebut ditutup untuk umum. Penduduk kampung Pugeran yang tidak mengungsi ke luar kota, mereka memilih mengungsi di Pastoran Pugeran. Dengan begitu, persediaan makanan juga harus ditambah seiiring dengan bertambah banyak pengungsi yang datang ke pastoran Pugeran.

${ }_{23}$ Paroki Pugeran, 60 Tahun Gereja Hati Kudus Yesus Pugeran 1934-1994, (Yogyakarta: Panitian, 1994), hlm. 8. 
Tetapi pada waktu itu tersiar kabar bahwa Liem Swan Bing dan Den Ayu Selohadiningdyah memiliki persediaan makanan lima karung kedelai dan simpanan gabah di rumahnya. ${ }^{24}$

Setelah pertempuran sedikit reda Romo Sandiwan menemui pimpinan tentara Belanda untuk memberitahu keadaan pengungsi di Pastoran Pugeran. Romo Sandiwan ingin meminta ijin untuk membuka rumah Liem Swan Bing dan Den Ayu Selohadiningdyah untuk mencari bahan makanan. Usaha dari Romo Sandiwan mengalami kegagalan, akan tetapi pada keesokan harinya Romo Sandiwan mencoba datang kembali untuk menemui para penguasa di Pojok Benteng. Akan tetapi. Romo Sandiwan oleh Belanda diminta untuk segera mengungsi ke tempat yang aman. Romo Sandiwan menolak perintah Belanda. Kemudian tentara Belanda memeriksa gereja Pugeran untuk memastikan keadaan di Gereja Pugeran.

Setalah melihat keadaan Gereja Pugeran, Belanda memperbolehkan Gereja Pugeran tetap berdiri dengan syarat rumah-rumah milik pengungsi harus dibakar untuk keperluan strategi perang Belanda. Romo Sandiwan menyetujui syarat Belanda agar keselamatan dan logistik untuk para pengungsi terjamin. Pihak Belanda membuka gudang dan rumah yang berisi kedelai dan kacang tanah milik orang Cina. Bahan-bahan makanan tersebut kemudian diangkut di pastoran. Kesanggupan Romo Sandiwan untuk membantu Belanda membakar rumah-rumah penduduk tidak dilaksanakan tepat waktu. Alasan tersebut dilakukan agar rumah-rumah penduduk tidak dibakar karena apabila dibakar akan mengenai bangunan gereja. Akhirmya, rumah-rumah penduduk hanya dirobohkan dengan maksud supaya dapat dibangun kembali pasca perang kemerdekaan.

Misa Natal yang jatuh pada 25 Desember 1948 diwarnai serangan Belanda. Setelah misa selesai, para jemaat tidak berani pulang mereka mengungsi di pastoran sehingga jumlah pengungsi menjadi semakin banyak. Banyak korban yang meninggal akibat serangan Belanda. Romo sandiwan beserta panitia pengungsi mengubur mayat-mayat korban serangan Belanda. Selain itu membuat usungan untuk mengangkat para korban yang terluka dan dibawa ke Rumah Sakit Panti Rapih.

\section{E. Simpulan}

Yogyakarta merupakan salah satu satu kota yang menjadi saksi perjuangan para rakyat dalam mempertahankan kemerdekaan Indonesia. Setelah proklamasi kemerdekaan Indonesia, Yogyakarta menjadi ibu kota negara Republik Indonesia karena situasi di Jakarta kacau. Kantor pusat pemerintahan yaitu berada di Gedung Agung. Terdapat beberapa faktor yang kuat sehingga kota Yogyakarta dijadikan sebagai ibu kota negara menggantikan kota Jakarta. Pasca perpindahan ibu kota negara Indonesia ke Yogyakarta banyak dampak yang bermunculan. Diantaranya adalah melonjaknya pertumbuhan penduduk akibat migrasi besar-besaran penduduk dari berbagai daerah untuk mencari perlindungan di Yogyakarta.

${ }^{24}$ Th. Endang Ratnaningsih, "Sejarah Perkembangan Gereja Hati Kudus Tuhan Yesus Pugeran tahun 1934-1994”, Skripsi, (Yogyakarta: Universitas Sanata Dharma, 1994), hlm. 140. 
Ambisi Belanda untuk menguasai kembali Indonesia, terlihat dengan adanya serangan Agresi Militer Belanda I pada tanggal 21 Juli 1947. Diplomasi yang dilakukan oleh kedua belah pihak tidak membuahkan hasil yang menguntungkan Indonesia. Kemudian keadaan diperparah dengan Belanda membatalkan perjanjian Renville secara sepihak dan melakukan serangan Agresi Militer Belanda ke II. Serangan Agresi Militer Belanda ke II. Sasaran dari Agresi Militer Belanda ke II yaitu kota Yogyakarta dikarenakan Belanda berharap dapat menguasai kota Yogyakarta. Pemimpin pada saat itu menjadi segera mengambil keputusan untuk mendirikan pemerinthan darurat di Bukittinggi.

Dalam Perang Kemerdekaan II, seluruh lapisan masyarakat terlibat tidak terkecuali Pasuka Polisi Pelajar Pertempuran (P3). Pasukan ini merupakan pasukan Mobile Briagade (Mobbrig) di bawah pimpinan IP II Djohan Soeparno. Pasukan ini bermarkas di SPN Ambarukmo Yogyakarta. Setelah terdesak oleh Belanda, akhirnya pasukan P3 mundur dan bermarkas di Banyakan Bantul. Peranan dari Pasukan P3 adalah membantu pasukan yang tersisa di kota menghambat laju pasukan Belanda yang akan menguasai kota Yogyakarta. Perjalanan Pasukan P3 dalam menghambat pasukan Belanda yaitu dari sekitar Ambarukmo- Gendeng Timoho- Lempuyangan- Gondomanan- Imogiri- Karangsemut- dan pada akhirnya sampai ke Banyakan,

Setelah mendapat serangan dari tentara Belanda, tentara Indonesia beserta dengan rakyat melakukan serangan balasan di semua tangsi Belaanda Serangan dilakukan pada 29 desember 1948. Hasil dari serangan tersebut tentara Indonesia berhasil menguasai tangsi-tangsi Belanda. Setelah dibagi menjadi beberapa Sub Wehkreise (SWK), pasukan P3 masuk ke dalam SWK 102 karena letak markasnya berada di Banyakan Bantul dan di bawah pimpinan Mayor Sardjono. Pasukan P3 juga berperan dalam Serangan Umum 1 Maret 1949. Mereka dibagi dalam beberapa lokasi diantaranya yaitu Pojok Benteng Wetan, Kotagede, Pleret, dan Karangsemut. Serangan yang dilakukan P3 cukup melelahkan bagi Belanda.

Perang Kemerdekaan II juga melibatkan seluruh lapisan masyarakat. Salah satunya yaitu peran dari Gerja Pugeran yang terletak di Pugeran Bantul. Pada saat perang gereja ini berfungsi sebagai tempat pengungsian, rumah sakit, dan dapur umum. Di dalam gereja ini juga tinggal banyak tentara yang meminta perlindungan pada siang hari. Gereja juga menyediakan bahan makan untuk para pengungsi. Bahan makanan tersebut didapat dari masyarakat sekitar atas izin Belanda.

\section{DAFTAR PUSTAKA}

Abdul Haris Nasution, Sekitar Perang Kemerdekaan Indonesia Jilid II, Bandung: Angkasa, 1974.

Atim Supomo, Djumarwan, dan Masqudori, Brimob Polri Jateng dan DIY dalam Lintasan Sejarah, Yogyakarta: Pustaka Pelajar, 1996.

Dharmono Hardjowidjono (ed), Replika Sejarah Perjuangan Rakyat Yogyakarta (Buku Ke-Satu), Yogyakarta: Dinas Sosial Propinsi Daerah Istimewa Yogyakarta, 1983. 
Gerilya Wehkreise III, Yogyakarta: Percetakan Keluarga,tt

Paroki Pugeran, 60 Tahun Gereja Hati Kudus Yesus Pugeran 1934-1994, Yogyakarta: Panitia, 1994.

Tashadi H, dkk, Buku Kenangan 50 Tahun Republik Indonesia di Yoyakarta sebuah Lintasan Sejarah, Yogyakarta: Panitia Gabungan Peringatan HUT ke-50 Kemerdekaan RI Bhakti Pertiwi Propinsi Daerah Istimewa Yogyakarta, 1995.

Tashadi dkk, Sejarah Revolusi Kemerdekaan (1945-1949) di DIY, Yogyakarta: Departeman Pendidikan dan Kebudayaan, 1986.

Th. Endang Ratnaningsih, "Sejarah Perkembangan Gereja Hati Kudus Tuhan Yesus Pugeran dari Tahun 1934-1994”, Skripsi, Yogyakarta: Universitas Sanata Daharma, 1994. 